\title{
Participação e cultura política: os conselhos municipais de desenvolvimento rural sustentável no território Portal da Amazônia
}

\author{
Alexandre de Azevedo Olival* \\ Andrezza Alves Spexoto** \\ José Alesando Rodrigues***
}

Resumo: Apesar de se constituírem em uma das mais importantes inovações institucionais na política brasileira, a profusão dos conselhos de gestão municipal não garante em si um aprimoramento da democracia brasileira. O objetivo do presente estudo foi avaliar o perfil dos conselhos de desenvolvimento rural sustentável e de seus conselheiros, identificando possíveis diferenças entre os representantes da sociedade civil e do poder público. Para isso foram aplicados questionários contendo questões abertas e fechadas para 100 conselheiros de 12 dos 16 municípios que formam o território Portal da Amazônia. Os resultados indicam que os conselheiros são formados por uma elite local, principalmente em relação à cultura política, havendo fortes diferenças entre os representantes da sociedade civil e do poder público, podendo indicar uma correlação de forças desigual dentro destes espaços de deliberação. Os resultados indicam ainda que grande parte dos conselhos ainda possui perfil consultivo e não desempenha seu papel de auxílio na formulação de planos de desenvolvimento, havendo pouca participação da população nas deliberações dos conselhos. Como conclusão,

\footnotetext{
*Mestre em Medicina Veterinária. Diretor/ Instituto Ouro Verde, Alta Floresta/ MT. alexandre.iov@terra.com.br

**Mestre em Medicina Veterinária. Diretora/ Instituto Ouro Verde, Alta Floresta/ MT. institutoouroverde@terra.com.br

*** Biólogo, Especialista em Educação Ambiental para conservação da Amazônia Mato-Grossense. Coordenador/ Projeto GESTAR Território Portal da Amazônia. gestarpa@icv.org.br
} 
1014 - Participação e cultura política: os conselhos municipais de desenvolvimento rural sustentável no território Portal da Amazônia

a pesquisa aponta a necessidade de implementação de estratégias para maior envolvimento da população e para a importância da capacitação dos conselheiros para o processo participativo.

Palavras-chave: desenvolvimento sustentável, conselhos, participação, cultura política.

Classificação JEL: R58 - Regional Development Policy”, dentro da categoria "Urban, Rural, and Regional Economics" e subcategoria "R5 Regional Government Analysis”.

Abstract: In spite of being one of the most important institutional innovations in the Brazilian politics, the profusion of municipal administration councils doesn't guarantee in itself an evolution in the Brazilian democracy. The aim of the present study was to evaluate the profile of the municipal councils of sustainable rural development and their counselors, identifying possible differences between the civil society representatives and the public power. For that were applied questionnaires containing open and closed questions for 100 counselors of 12 of the 16 municipal districts that form the Amazon Portal territory. The results indicate that the counselors are formed by local elite, mainly in relation to political culture, having big differences among the civil society representatives and the public power. The dates could indicate an unequal correlation of forces inside of these deliberation spaces. The results indicate although that great part of the counselors still possesses an advisory profile and doesn't play an important aid in the formulation of municipals development plans, having little participation of the population in the deliberations. As conclusion, the research emphasizes the need to implement strategies for larger involvement of the population and for the importance of the counselors' training for the participative process.

Key words: sustainable development, council, participation, politic culture.

Jel Classification: R58 - Regional Development Policy”, dentro da categoria “Urban, Rural, and Regional Economics” e subcategoria “R5 Regional Government Analysis”.

RER, Rio de Janeiro, vol. 45, no 04, p. 1013-1035, out/dez 2007 - Impressa em novembro 2007 


\section{Introdução}

A forma "conselho" utilizada na gestão pública, ou em coletivos organizados da sociedade civil, não é nova na história. Os conselhos são uma invenção tão antiga quanto a própria democracia participativa. Na modernidade, surgiram em épocas de crises políticas e institucionais, conflitando com as organizações de caráter mais tradicional. Neste sentido poderiam ser pensados como uma estratégia de colaboração entre diferentes atores sociais ou tidos como caminhos para as mudanças sociais no sentido de democratização das relações de poder dentro da sociedade (Gohn, 2000).

Especificamente no Brasil, o processo de democratização política vivenciado a partir das décadas de 1980 e 1990, fruto da pressão de movimentos populares, abriu espaço para a criação de uma série de experiências de participação popular nas arenas públicas de decisão política, com, por exemplo, a estruturação dos diferentes conselhos municipais de gestão, como os de saúde, os de educação e, posteriormente, os de desenvolvimento rural sustentável (Labra e Figueiredo, 2002).

Esta profusão de conselhos gestores pode ser compreendida como a mais importante inovação institucional das políticas públicas no Brasil democrático uma vez que encerram em si um enorme potencial de transformação política, propiciando a entrada de temas políticos na vida de indivíduos ou grupos organizados que até então se encontravam às margens desta discussão (Abramovay, 2001).

No entanto, os conselhos de gestão pública não são virtuosos em si. Tornam-se virtuosos na medida em que são percebidos como espaços de decisão construídos pela capacidade efetiva de atuação da representação popular da coletividade (Bava, 2001), ou seja, os conselhos desempenham um papel inovador dentro da democracia no país na medida em que conseguem, através de um aprimoramento nos processos de representação e participação da população, interferir diretamente nas decisões políticas.

Entretanto, alguns limitantes têm sido apontados neste sentido. Muitos conselhos são formados estritamente como contra-partida à exigência legal para a obtenção de recursos públicos por parte dos municípios e não expressam uma dinâmica social significativa (Abramovay, 
1016 - Participação e cultura política: os conselhos municipais de desenvolvimento rural sustentável no território Portal da Amazônia

2001). Além disso, apesar da transferência de regras formais, estruturas administrativas e procedimentos burocráticos, não é possível a transferência por parte do governo federal para os municípios de valores, comportamentos, coesão social e confiança entre os indivíduos. Com estas "falhas nas transferências institucionais" corre-se o risco que os conselhos sejam apenas uma nova formalidade a ser cumprida para a obtenção de recursos públicos (Greif , 2001).

Especificamente em relação aos Conselhos Municipais de Desenvolvimento Rural Sustentável (CMDRS), a sua estruturação relaciona-se com a implantação do Programa Nacional de Fortalecimento da Agricultura Familiar (PRONAF), que indicou novas bases para a formulação das políticas públicas de desenvolvimento rural (Marques e Flexor, 2006). O programa parte da proposta de privilegiar a agricultura familiar no desenvolvimento rural, indicando as instâncias locais participativas (conselhos) como espaço apropriado para a manifestação de interesses e a tomada de decisão democrática. De fato, além de aprovar, acompanhar e avaliar os planos municipais de desenvolvimento rural, os CMDRS teriam o papel de controlar os gastos e a destinação dos recursos, numa abordagem de "gestão pública do orçamento público" (Governo Federal, 1995).

Entretanto, alguns pontos podem ser identificados como estrangulamentos do papel dos conselhos como instrumentos de democratização de poder. De um lado, Fuks et al. (2003) destacam os estudos sobre cultura política, entendida como os valores, sentimentos, crenças e conhecimentos relevantes e que explicam, em parte, os padrões de comportamento político adotados pelos sujeitos. De acordo com este referencial, a distribuição desigual de recursos cívicos em uma população poderia explicar o seu comportamento também desigual em relação à participação política. Assim, mais do que simplesmente enquadrar as diferentes sociedades em uma tipologia construída com base em características externas, os estudos de cultura política podem servir para que se construa uma compreensão da realidade que considere as diferentes experiências históricas dos sujeitos e sua relação com o comportamento político desempenhado na sociedade (Castro, 2000).

Outras questões que se apresentam são a representatividade e o exercício de participação. Muitos movimentos populares, após as lu-

RER, Rio de Janeiro, vol. 45, no 04, p. 1013-1035, out/dez 2007 - Impressa em novembro 2007 
tas na década de 1980, perderam visibilidade na sociedade brasileira. Assim, muitos conselhos acabaram perdendo sua base política de sustentação sobre a qual tinham forjado uma identidade própria. Desta forma, acabaram comprometendo também a sua representatividade e, consequentemente sua experiência participativa, junto aos conselhos gestores (Gerschman, 2004).

Estes pontos são importantes uma vez que os conselhos devem ser entendidos como uma instância de exercício de poder, onde a distribuição desigual dos recursos tem como conseqüência a distribuição desigual também de poder, sendo que as práticas de participação neste espaço podem concorrer para a democratização das relações ou, ao contrário, para perpetuar as desigualdades e a submissão (Wendhausen e Caponi, 2002).

Considerando os pontos discutidos, o objetivo deste estudo foi identificar o perfil dos conselheiros municipais de desenvolvimento rural sustentável nos municípios que formam o território Portal da Amazônia, destacando a distribuição dos diferentes recursos para o exercício da representação e da prática política e identificando diferenças entre os representantes da sociedade civil e os representantes do poder público. $\mathrm{O}$ estudo indica algumas estratégias de aprimoramento deste instrumento de gestão municipal.

\section{Metodologia}

A pesquisa foi realizada no território Portal da Amazônia, região formada por 16 municípios localizados no extremo-norte de Mato Grosso. O Portal da Amazônia caracteriza-se por ser uma área de colonização recente, com municípios formados a partir de projetos de colonização públicos e privados iniciados na década de 1970. Localiza-se no chamado "arco do desmatamento da floresta amazônica", área de intensos conflitos sócio ambientais na qual o avanço da produção agropecuária pressiona as áreas de preservação ambiental. Dos 16 municípios que fazem parte do Portal da Amazônia, foram visitados 12 CMDRS.

Para o levantamento de dados foram utilizados questionários previamente testados contendo questões abertas e fechadas. Os questionários foram aplicados durante as reuniões ordinárias dos CMDRS 
1018 - Participação e cultura política: os conselhos municipais de desenvolvimento rural sustentável no território Portal da Amazônia

pesquisados. Neste momento, um pesquisador fazia a introdução da pesquisa, destacando seus objetivos, a importância da participação dos conselheiros e fornecia uma visão geral das questões a serem respondidas, seguindo as recomendações citadas em Lakatos e Marconi (1996). A aplicação dos questionários ocorreu entre os meses de outubro e dezembro de 2005, sendo que cada conselho foi visitado uma vez durante este período.

Os questionários possuíam questões divididas em 4 conjuntos, a saber: perfil socioeconômico do conselheiro, aspectos relacionados à cultura política (interesse por política antes e depois da participação nos conselhos, engajamento cívico, percepção sobre a capacidade de interferência nas decisões do município e do próprio conselho), aspectos relacionados à representatividade (encontros com a base de representação) e percepções sobre o papel dos conselhos no desenvolvimento da região.

Para a realização das análises estatísticas todos os dados foram transformados em variáveis dicotômicas. O nível de interesse por política antes e depois da participação nos conselhos foi transformado em uma variável ordinal, sendo que para os itens muito alto, alto, médio, pouco ou muito pouco foram considerados os valores $5,4,3,2,1$ e, respectivamente.

Para a análise estatística dos resultados utilizaram-se os testes de Chi Quadrado, Mann Whithney e Wilcoxon. Foram utilizados testes não paramétricos tendo em vista a distribuição não normal das variáveis estudadas (dicotômicas e/ou ordinais). Os testes foram realizados utilizando o programa EPI INFO 2000 e SPSS versão 12.

Para as análises estatísticas consideraram-se dois grupos de conselheiros: os representantes da sociedade civil (representantes de sindicatos, associações, cooperativas, igrejas e outros grupos organizados presentes nos conselhos) e os representantes do poder público, compreendidos pelos funcionários de prefeituras (concursados ou por indicação), órgão de extensão rural e defesa animal, além de representantes do Instituto Nacional de Colonização e Reforma Agrária (INCRA). A Tabela 01 apresenta a listagem de todos os conselheiros participantes da pesquisa e suas características principais. 


\section{Resultados e Discussão}

\subsection{Perfil dos conselhos e dos conselheiros}

Dentro do território Portal da Amazônia, 90\% dos conselhos visitados tinham como presidente representantes do poder público, sendo que em $80 \%$ este presidente era o próprio Secretário Municipal de Agricultura. Não foi constatada a ocorrência de um agricultor familiar como presidente do CMDRS. As instituições representadas dentro dos conselhos estão expostas na Tabela 02. Verificou-se a predominância da representação dos agricultores familiares através de algumas associações, muito embora um número extremamente reduzido de associações existentes no território esteja representado. Do ponto e vista do poder público destaca-se a elevada porcentagem de representantes dos órgãos técnicos de apoio à produção (EMPAER, INDEA, CEPLAC) e a ausência de outras representações, como o setor da educação ou saúde.

O perfil dos conselheiros demonstra elevada participação dos homens em relação às mulheres $(91,92 \%$ dos participantes da pesquisa eram do sexo masculino). Com respeito ao local de moradia, 58,16\% dos conselheiros relataram morar na área urbana dos municípios e somente $38,78 \%$ nas áreas rurais. A idade média dos conselheiros ficou em 49 anos. A distribuição dos conselheiros de acordo com a profissão está exposta a Tabela 03.

Estes dados estão de acordo com o levantamento realizado por Schneider et al. (2004), que demonstra que os conselhos municipais de desenvolvimento rural sustentável não representam a totalidade da população rural, com suas especificidades. No caso específico dos conselhos do Portal da Amazônia, verifica-se a predominância quase absoluta de homens, acima dos 40 anos e uma predominância da representação de associações em detrimento do sindicato de trabalhadores rurais e movimentos sociais, além da representação dos órgãos técnicos de apoio à produção, podendo indicar o predomínio das discussões produtivas e técnicas em detrimento das questões mais amplas sobre o desenvolvimento rural da região.

RER, Rio de Janeiro, vol. 45, no 04, p. 1013-1035, out/dez 2007 - Impressa em novembro 2007 
Tabela 01 - Conselhos municipais de desenvolvimento rural sustentável dos municípios que formam o Portal da Amazônia participantes da pesquisa ${ }^{1}$.

\begin{tabular}{|c|c|c|c|c|c|c|c|}
\hline \multirow{2}{*}{ Município } & \multirow{2}{*}{$\begin{array}{l}\text { Tempo de } \\
\text { existência } \\
\text { do CMDR }\end{array}$} & \multirow{2}{*}{$\begin{array}{c}\text { Número } \\
\text { total de } \\
\text { conselheiros }\end{array}$} & \multicolumn{4}{|c|}{$\begin{array}{l}\text { Número de conselheiros } \\
\text { participantes da pesquisa }\end{array}$} & \multirow{2}{*}{$\begin{array}{l}\text { Freqüiência das } \\
\text { reuniões }\end{array}$} \\
\hline & & & $\begin{array}{c}\text { Sociedade } \\
\text { Civil }\end{array}$ & $\begin{array}{l}\text { Poder } \\
\text { Público }\end{array}$ & $\begin{array}{l}\text { Não } \\
\text { soube }\end{array}$ & Total & \\
\hline Alta Floresta & 103 & 11 & 7 & 3 & 1 & 11 & esporádicas \\
\hline Carlinda & 29 & 9 & 3 & 5 & 1 & 9 & mensais \\
\hline Marcelândia & 31 & 10 & 1 & 4 & 1 & 6 & mensais \\
\hline Matupá & 50 & 14 & 1 & 6 & 2 & 9 & mensais \\
\hline Nova Bandeirantes & 103 & 8 & 4 & 3 & 2 & 9 & mensais \\
\hline Nova Canaã do Norte & 50 & 18 & 4 & 4 & 1 & 9 & mensais \\
\hline Nova Monte Verde & 23 & 12 & 3 & 3 & 1 & 7 & mensais \\
\hline Nova Santa Helena & 48 & 12 & 2 & 6 & 1 & 9 & bimestrais \\
\hline Novo Mundo & 30 & 10 & 7 & 1 & 2 & 10 & mensais \\
\hline Paranaíta & 29 & 7 & 1 & 1 & 3 & 5 & esporádicas \\
\hline Peixoto de Azevedo & 100 & 8 & 3 & 3 & 2 & 8 & mensais \\
\hline Terra Nova do Norte & 132 & 11 & 5 & 2 & 1 & 8 & esporádicas \\
\hline
\end{tabular}

Tabela 02 - Instituições da sociedade civil e do poder público representadas nos conselhos municipais de desenvolvimento rural do território Portal da Amazônia.

\begin{tabular}{l|c|l|c}
\hline \multicolumn{2}{c|}{ Sociedade Civil } & \multicolumn{2}{c}{ Poder Público } \\
\hline $\begin{array}{c}\text { Organização, Setor, } \\
\text { Instituições }\end{array}$ & \% de conselheiros & $\begin{array}{c}\text { Organização, Setor, } \\
\text { Instituições }\end{array}$ & $\%$ de conselheiros \\
\hline Associações & $25,27(25)$ & Prefeituras $^{2}$ & $26,37(26)$ \\
STRs $^{1}$ & $8,79(9)$ & EMPAER $^{2}$ & $9,89(10)$ \\
Cooperativas $_{\text {Sindicato Rural }}$ & $5,49(5)$ & INDEA $^{3}$ & $6,59(7)$ \\
Sem instituição definida & $2,20(2)$ & CEPLAC $^{4}$ & $1,1(1)$ \\
Igreja & $2,20(2)$ & INCRA $^{5}$ & $1,1(1)$ \\
\hline
\end{tabular}

1. Sindicatos dos Trabalhadores Rurais; 2. Empresa Mato-grossense de Pesquisa e Extensão Rural; 3. Instituto de Defesa Agropecuária do Estado de Mato Grosso; 4. Comissão Executiva do Plano da Lavoura Cacaueira; 5. Instituto Nacional de Colonização e Reforma Agrária

${ }^{1}$ Os municípios de Apiacás, Colíder, Guarantã do Norte e Nova Guarita, que compõem o território Portal da Amazônia não participaram da pesquisa por não terem realizado reunião ordinária do CMDRS durante o período de execução do trabalho. 
Tabela 03 - Profissão declarada dos conselheiros dos CMDRS dos municípios que formam o território Portal da Amazônia.

\begin{tabular}{l|c}
\hline \multicolumn{1}{c|}{ Profissão } & \% em relação ao total de respostas válidas \\
\hline Agricultor ou produtor rural & 42,39 \\
Funcionário público com & 29,35 \\
concurso & 8,70 \\
Profissional liberal & 7,61 \\
Gestor público & 10,86 \\
Outras & 1,09 \\
Não Soube & 100,00 \\
\hline Total & \\
\hline
\end{tabular}

Com relação ao tempo de participação nos conselhos, os conselheiros participavam, em média, a 32 meses dos CMDRS. No entanto, $41,18 \%$ dos entrevistados relataram estarem a menos de 12 meses no conselho. Não houve diferença entre a distribuição dos meses de conselho de acordo com o tipo de representação (sociedade civil ou poder público), com $\mathrm{P}>0,05$ para todos os casos.

Encontrou-se associação entre a freqüência de entrevistados representantes do poder público e a freqüência de entrevistados que relataram morar nas áreas urbanas dos municípios. O mesmo foi identificado em relação à freqüência de representantes da sociedade civil e os moradores das áreas rurais $(\mathrm{P}<0,001$ para ambos os casos), indicando haver diferenças entre o local de moradia de cada representação.

Com respeito à renda domiciliar dos conselheiros, observa-se que grande parte dos entrevistados possui renda entre 03 a 05 salários mínimos. Considerando os dados do IBGE, pode-se dizer que a renda média dos conselheiros está dentro da faixa que compreende a renda média nos municípios participantes (3,63 salários mínimos, IBGE, 2000). Cabe destacar, no entanto, que houve associação estatisticamente significante entre a freqüência de entrevistados que eram representantes da sociedade civil organizada e a freqüência de entrevistados que relataram renda mensal de até 02 salários mínimos, demonstrando que, enquanto os representantes do poder público que participam do conselho possuíam uma renda variada, mas em média superior a 02 salários mínimos, os representantes da sociedade civil possuíam renda inferior à média do território (Tabela 04). 
Com respeito à escolaridade, o perfil dos conselheiros é bastante diferenciado em relação à população média nacional (Tabela 05). Não havia analfabetos e mais de $20 \%$ possuíam mais de 12 anos de estudos. Foi identificada associação estatística entre a freqüência de entrevistados que representavam a sociedade civil e a freqüência de entrevistados com até quatro anos de estudos $(\mathrm{P}<0,05)$. Também houve associação estatística entre a freqüência de entrevistados representantes do poder público e a freqüência de entrevistados com mais de 12 anos de estudo $(P<0,001)$.

Tabela 04 - Renda domiciliar dos participantes dos CMDRS dos municípios que formam o Portal da Amazônia.

\begin{tabular}{l|c}
\hline \multicolumn{1}{c|}{ Renda } & \% em relação ao total de respostas válidas \\
\hline Até 02 salários mínimos & 17,20 \\
De 03 a 05 salários mínimos & 51,61 \\
De 06 a 10 salários mínimos & 22,58 \\
Mais de 10 salários mínimos & 5,38 \\
Não Sabe/ Não respondeu & 3,23 \\
\hline Total & 100,00 \\
\hline
\end{tabular}

Tabela 05 - Número de anos de estudo dos conselheiros do CMDRS dos municípios que formam o território do Portal da Amazônia.

\begin{tabular}{l|c}
\hline \multicolumn{1}{c|}{ Anos de Estudo } & \% em relação ao total de respostas válidas \\
\hline Nenhum & $1,05 \%$ \\
De 1 a 4 anos & $16,84 \%$ \\
De 5 a 8 anos & $21,05 \%$ \\
De 9 a 12 anos & $40,00 \%$ \\
Mais de 12 anos & $21,05 \%$ \\
Não sabe/ Não respondeu & $0,00 \%$ \\
\hline Total & 100,00 \\
\hline
\end{tabular}

Com relação à cultura política, foram pesquisados o interesse atual por política e o engajamento cívico, manifestados através do associativismo e cooperativismo e pela filiação partidária, além da participação em outros conselhos de gestão municipal. Desta forma, apesar de não ter sido observada associação estatística entre o tipo de representação 
e o maior ou menor interesse por política ( $\mathrm{P}=0,281$ para o interesse alto e baixo), observou-se o elevado interesse médio por política no público pesquisado uma vez que $40 \%$ dos respondentes declararam que possuíam interesse alto ou muito alto. Aproximadamente $15 \%$ dos respondentes declararam interesse baixo ou muito baixo por política. É interessante observar que Moisés (1995), ao estudar o interesse por política a nível nacional, demonstrou que cerca de $30 \%$ da população declararam não possuir qualquer interesse por atividades políticas. Estes dados indicam que o interesse é elevado e está distribuído de forma igualitária entre representantes do poder público e representantes da sociedade civil (Tabela 06).

Tabela 06 - Nível de interes se por política dos conselheiros dos CMDRS dos municípios que formam o território Portal da Amazônia.

\begin{tabular}{l|c}
\hline Interesse por Política & \% em relação ao total de respostas válidas \\
\hline Muito Grande & $18,75 \%$ \\
Grande & $23,96 \%$ \\
Médio & $40,63 \%$ \\
Pouco & $5,21 \%$ \\
Muito Pouco & $11,45 \%$ \\
Não soube/ Não respondeu & $0,00 \%$ \\
\hline Total & 100,00 \\
\hline
\end{tabular}

Cada entrevistado participa em média de dois conselhos de gestão municipal. No entanto, os dados revelam associação estatisticamente significativa entre a freqüência de entrevistados que representavam o poder público local e aqueles que relataram atuar em mais de um conselho $(P=0,005)$. O inverso ocorreu com os representantes da sociedade civil $(P=0,005)$. Assim, pode-se dizer que os representantes da sociedade civil tendem a participar somente do CMDRS enquanto os representantes do poder público acabam atuando em mais de um conselho de gestão municipal (Tabela 07). 
Participação e cultura política: os conselhos municipais de desenvolvimento rural sustentáve no território Portal da Amazônia

Tabela 07 - Número de participações dos conselheiros dos CMDRS dos municípios que formam o território Portal da Amazônia em outras formas de organização social.

\begin{tabular}{l|c}
\hline \multicolumn{1}{c|}{$\begin{array}{c}\text { Número de Organizações em que } \\
\text { Participa }\end{array}$} & $\begin{array}{c}\text { \% em relação ao total de respostas } \\
\text { válidas }\end{array}$ \\
\hline 0 & $9,0 \%$ \\
1 & $45,0 \%$ \\
2 & $28,0 \%$ \\
3 & $18,0 \%$ \\
\hline Total & $100,0 \%$ \\
\hline
\end{tabular}

Em relação à participação em outras formas de organização, observou-se que $38,36 \%$ dos entrevistados relataram estarem inscritos em associações e $18,24 \%$ em cooperativas. Outros grupos pesquisados foram os grupos religiosos $(24,53 \%)$ e os grupos de lazer $(6,29 \%) ; 10,06 \%$ citaram ainda outros grupos enquanto $2,52 \%$ não souberam responder à questão. Houve associação estatística entre a freqüência de entrevistados representantes da sociedade civil e a freqüência de entrevistados participantes de associações ou cooperativas $(\mathrm{P}<0,001)$. Não houve associação estatística entre o tipo de representação e o número de participação em outras organizações $(\mathrm{P}>0,005)$. Observa-se que $73 \%$ dos respondentes relataram participar de uma a duas organizações e $18 \%$ em três organizações. Somente $9 \%$ dos participantes da pesquisa relataram não participar de nenhuma organização em sua comunidade/ município.

Os dados sobre filiação partidária reforçam o quadro de engajamento cívico da população pesquisada, com mais de $64 \%$ dos conselheiros estando inscritos em algum partido político, conforme dados apresentados na Tabela 08. Dos representantes da sociedade civil, cerca de $69 \%$ estão inscritos em algum partido político e dos representantes do poder público, cerca de $60 \%$ estão inscritos.

Não existem dados disponíveis sobre o associativismo e o engajamento cívico na região ou mesmo no Estado de Mato Grosso para fins de comparação. Utilizando os dados do IBGE sobre as principais capitais brasileiras (IBGE, 1996), observa-se que nestas capitais, somente $27 \%$ da população eram filiados à alguma associação, sendo que somente $3 \%$ eram filiados a algum partido político específico (Santos Júnior, 2001). 
No caso dos conselheiros do Portal da Amazônia a diferença é bastante expressiva: somente $9 \%$ não estavam ligados à alguma forma de organização e 35,48\% não estavam filiados a algum partido político.

Conforme apontado por Fuks et al. (2003), a competência política subjetiva é um termo que designa a percepção dos atores acerca do seu próprio papel dentro do sistema político. Trata-se de uma autoavaliação realizada pelos indivíduos sobre sua atuação diante dos fatos e objetos políticos, em especial sobre a sua capacidade de influenciar a tomada das decisões. Neste sentido, foi pesquisada a competência política subjetiva em relação às decisões do conselho e às decisões políticas do município como um todo.

A Tabela 09 demonstra que, tanto nos conselhos quanto no município, é alta a percepção de competência política por parte dos conselheiros, sendo ligeiramente maior a percepção de influência dentro do próprio conselho do que no município como um todo.

Tabela 08 - Filiação partidária dos conselheiros dos CMDRS dos municípios que formam o território Portal da Amazônia.

\begin{tabular}{l|c}
\hline \multicolumn{1}{c|}{ Filiação Partidária } & $\begin{array}{c}\text { \% em relação ao total de respostas } \\
\text { válidas }\end{array}$ \\
\hline PT & 4,30 \\
PSDB & 3,23 \\
PMDB & 4,30 \\
PPS & 12,90 \\
PTB & 9,68 \\
PDT & 1,08 \\
PV & 4,30 \\
PFL & 7,53 \\
PL & 7,53 \\
PP & 3,23 \\
PSB & 3,23 \\
Partido não especificado & 3,23 \\
Não é filiado a partido algum & 35,48 \\
\hline Total & 100,00 \\
\hline
\end{tabular}

Houve associação estatística entre a freqüência de entrevistados que relaram representar órgãos do poder público e aqueles que relataram 
ter alta capacidade de influenciar nas decisões políticas do município (P $=0,034)$. Também houve associação estatística entre a freqüência de entrevistados representantes da sociedade civil e aqueles que relataram possuir média capacidade de influenciar nas decisões do município ( $\mathrm{P}$ $=0,021)$. Este fato pode demonstrar que existe uma diferença entre estes dois grupos de representação, sendo que os representantes do poder público possuem uma percepção maior de interferência nas decisões municipais do que os representantes da sociedade civil. Marques e Flexor (2006), analisando o perfil de diversos CMDRS do Brasil destacaram que o controle de muitos conselhos por parte do poder público local, através da indicação de representantes e da presidência do conselho, pode contribuir para que estes se sintam mais capazes de influenciar nas decisões políticas dos municípios.

Tabela 09 - Auto-avaliação sobre a capacidade de influência nas decisões políticas dos conselhos municipais de desenvolvimento rural sustentável e do município por parte conselheiros dos CMDRS dos municípios que formam o território Portal da Amazônia.

\begin{tabular}{l|c|c}
\hline \multirow{2}{*}{ Interesse por Política } & \multicolumn{2}{|c}{ \% em relação ao total de respostas válidas } \\
\cline { 2 - 3 } & Influência no Município & Influência no Conselho \\
\hline Muito Grande & $18,75 \%$ & $15,31 \%$ \\
Grande & $28,13 \%$ & $40,82 \%$ \\
Médio & $37,50 \%$ & $38,78 \%$ \\
Pouco & $9,38 \%$ & $5,10 \%$ \\
Muito Pouco & $3,13 \%$ & $0,00 \%$ \\
Não soube/ Não respondeu & $3,13 \%$ & $0,00 \%$ \\
\hline Total & $100,00 \%$ & $100,00 \%$ \\
\hline
\end{tabular}

Apesar desta diferença interna nos conselhos, novamente deve-se ressaltar a diferença entre o perfil geral dos conselheiros e a população em geral no Brasil. Moisés (1995) demonstrou que 57,8\% dos entrevistados afirmaram que não eram capazes de influenciar nas decisões políticas de seu município, número muito acima da média encontrada entre os conselheiros do Portal da Amazônia.

Os dados até aqui apresentados revelam primeiramente que o grupo de conselheiros pesquisados constitui-se de uma elite, principalmente 
quando considerada a cultura política. Deve-se ressaltar, no entanto, as diferenças existentes dentro dos conselhos, com maior discrepância entre os representantes do poder público, com maior renda, escolaridade, com moradia nas áreas urbanas e maior percepção de capacidade de influenciar nas políticas municipais em relação aos representantes da sociedade civil. Atenta-se ainda para a pequena participação das mulheres nos CMDRS avaliados. Estes dados estão de acordo com os dados apresentados por Tatagiba (2005), uma vez que, segundo a autora "os conselheiros, no que se refere à renda, escolaridade e engajamento político-partidário, estão bem acima da média nacional. A heterogeneidade na composição, verificada pela diversidade das organizações representadas nos conselhos, caminha, assim, ao lado de uma tendência à elitização da participação".

Desta forma, considerando que grupos dotados de recursos políticos desiguais possuem capacidades também desiguais para atuar nos conselhos, pode-se dizer que as diferenças encontradas no perfil dos representantes do poder público e da sociedade civil organizada podem indicar uma maior capacidade de influência e interferência nas decisões daqueles representantes do poder público.

Conforme aponta Fuks et al. (2003), sendo os conselhos dependentes de trabalho voluntário e constituídos por representantes da sociedade civil, a tendência é que ele não tenha uma participação difusa da população, Desta forma, o autor sugere repensar o conceito dos conselhos como uma instituição caracterizada pela participação ampliada uma vez que a existência destas instituição não conseguiu superar ainda a distinção entre uma minoria de cidadãos politicamente ativos e a maioria passiva. Tatagiba (2005) reforça ainda que, como experiências que acompanham e particularizam o processo de redemocratização no Brasil, os conselhos são também espelhos que refletem as dimensões contraditórias de que se revestem nossas experiências democráticas recentes. Os dados apresentados permitem dizer que, nos conselhos de desenvolvimento rural sustentável do território Portal da Amazônia, estas contradições também são aparentes.

Assim, o predomínio de homens, mais velhos, melhor educados, com salários diferenciados e com maior cultura política, conforme apontado por Gerschamn (2004), reflete na verdade o próprio processo de representação em sociedades desiguais. Conforme destacado pelo autor, 
sem contar com a participação dos diferentes segmentos da população, os conselhos gestores transformam-se em meros espaços burocráticos de elaboração e execução de projetos setoriais e de legitimação de um discurso governamental que prega a participação e a cidadania.

\subsection{Influência das instituições na cultura política e suas mediações}

Foi pesquisada a participação no conselho como instrumento de aumento de cultura política, entendida como o aumento pelo interesse por política e o fortalecimento de ações junto à população local. Também foram pesquisadas as percepções sobre o papel dos conselhos nos municípios e os principais entraves para o seu pleno funcionamento.

Considerando a mudança de interesse por política após a participação no CMDRS, o teste de Wilcoxon demonstra que as distribuições das notas dadas pelo interesse por política não são estatisticamente diferentes, tanto antes quanto depois da participação no CMDRS $(P=0,560)$. Este fato se deve uma vez que, embora 24 respondentes tenham relatado aumento de interesse em política após a participação no conselho (22,34\%), 14 relataram o oposto, estando com menos interesse atualmente $(14,89 \%)$. Considerando o tipo de representação (sociedade civil ou poder público), também não houve diferença entre o interesse por política antes ou depois ( $\mathrm{P}=0,199$ e $\mathrm{P}=0,646$ respectivamente). Desta forma, pode-se dizer que a participação nos conselhos não está interferindo no maior ou menor interesse por política na população estudada.

Com respeito ao papel do CMDRS para o município, apesar de 63,27\% dos entrevistados citarem ser este um órgão fundamental para o desenvolvimento da região, 26,53\% apontaram ser o conselho importante, mas ainda de pouca valia prática. É interessante notar que enquanto houve tendência de associação estatística entre a freqüência de entrevistados representantes da sociedade civil e a freqüência de entrevistados que acreditavam que o CMDRS era muito útil para o desenvolvimento da região ( $\mathrm{P}=0,061)$, o inverso ocorreu com os representantes do poder público, havendo associação com a freqüência de entrevistados que citaram que os CMDRS não eram muito úteis para o desenvolvimento da região $(P=0,043)$, ou seja, que ainda carecem de maior estruturação ou que são um entrave para o desenvolvimento (Tabela 10).

RER, Rio de Janeiro, vol. 45, no 04, p. 1013-1035, out/dez 2007 - Impressa em novembro 2007 
Tabela 10 - Percepção dos conselheiros dos municípios que formam o território Portal da Amazônia sobre o papel do CMDRS para o desenvolvimento da região.

\begin{tabular}{l|c}
\hline $\begin{array}{c}\text { Percepção sobre o papel do CMDRS } \\
\text { para o desenvolvimento da região }\end{array}$ & $\begin{array}{c}\text { \% em relação ao total de respostas } \\
\text { válidas }\end{array}$ \\
\hline Muito útil para o desenvolvimento & 63,27 \\
Importante, mas de pouca valia prática & 26,53 \\
Um entrave para o desenvolvimento & 1,02 \\
Não soube/ Não respondeu & 5,10 \\
\hline Total & 100,00 \\
\hline
\end{tabular}

Com relação às práticas de participação, observou-se que mais de $85 \%$ dos respondentes relataram apresentar sempre ou às vezes os resultados das reuniões do CMDRS para as suas bases. No entanto, é interessante observar que quando indagados sobre a freqüência destas reuniões com a base, somente $65 \%$ dos entrevistados relataram encontrar-se sempre ou pelo menos periodicamente com suas bases. Chama a atenção ainda que $20 \%$ dos conselheiros afirmaram que nunca se encontram com sua base de representação (Tabela 11).

Tabela 11 - Freqüência de realização de reuniões com as bases dos conselheiros para discussão de pontos relativos ao desenvolvimento sustentável.

\begin{tabular}{|c|c|c|}
\hline \multirow{2}{*}{$\begin{array}{c}\text { Freqüência de realização } \\
\text { das reuniões com a base de } \\
\text { representação }\end{array}$} & \multicolumn{2}{|c|}{ Reuniões com a base } \\
\hline & $\begin{array}{c}\text { Para repassar as } \\
\text { decisões do CMDRS }\end{array}$ & $\begin{array}{c}\text { Freqüiência de } \\
\text { encontros com a base }\end{array}$ \\
\hline Sempre & 63,27 & 31,58 \\
\hline Às Vezes & 22,45 & 33,68 \\
\hline De Vez em Quando & 8,16 & 12,63 \\
\hline Quase Nunca & 1,02 & 2,11 \\
\hline Nunca & 4,08 & 20,00 \\
\hline Não soube/ Não respondeu & 1,02 & 0,00 \\
\hline Total & 100,00 & 100,00 \\
\hline
\end{tabular}

Houve associação estatística entre a freqüência de conselheiros representantes da sociedade civil e do poder público e aqueles que relataram repassar para as suas bases as decisões do CMDRS sempre após 
as reuniões ( $\mathrm{P}=0,043$ para os representantes da sociedade civil e $\mathrm{P}=0,030$ para os representantes do poder público). Com respeito à freqüência de encontro com as bases, tanto para os representantes da sociedade civil quanto para os representantes do poder público houve associação estatística com o encontro "às vezes" ( $\mathrm{P}=0,019$ e $\mathrm{P}=$ 0,015 respectivamente), confirmando que os encontros para discussão sobre o CMDRS não ocorrem com freqüência, mas provavelmente somente após alguma discussão neste órgão.

Considerando que a representação está ligada a um processo de duplo sentido de comunicação de mensagens políticas (Costa, 1997) e que, de acordo com os dados apresentados, as reuniões com as bases de representação ocorrem no Portal da Amazônia mais no sentido de atualizar a população sobre as discussões que já foram realizadas do que no sentido de formular propostas e estratégias de desenvolvimento, pode-se demonstrar problemas com relação à própria representatividade dos conselheiros. Este fato pode estar na base de um dos principais problemas citados pelos conselheiros: o pouco comprometimento da população com as decisões do conselho, ou como mencionado por dois conselheiros "... fazer os produtores acreditar nas decisões do conselho..." e "...é verificar as pessoas que moram nos assentamentos, porque eles não aceitam as leis e querem fazer do jeito deles..”.

Pode-se perceber assim que os conselhos podem não estar sendo percebidos como um espaço para reflexão e produção de normas e leis adequadas à realidade local, mas, como destaca Schneider et al. (2004), apenas um espaço pré-formatado para discutir assuntos impostos pela esfera federal ou estadual.

Com relação ao principal papel do CMDRS para o município, não houve uma clara tendência da média dos entrevistados: enquanto $34,95 \%$ citaram o planejamento de projetos, $21,36 \%$ citaram a aprovação de projetos previamente definidos. A fiscalização de recursos municipais aparece com $22,85 \%$ das respostas enquanto a avaliação de projetos com 18,93\% . 1,46\% dos entrevistados citou não saber a função do CMDRS, enquanto 0,49\% não respondeu. Observa-se assim que ainda há um número significativo de conselheiros que atribuem um papel consultivo ao conselho, dando pareceres a projetos ou aprovando projetos previamente definidos. São poucos os que associaram a imagem do 
conselho a um órgão deliberativo, com poder de decisão e definição de políticas públicas. Não houve associação entre o tipo de representação e as diferentes percepções sobre o papel do CMDRS.

Quando indagados sobre os principais benefícios práticos originários das ações do CMDRS nos municípios, os conselheiros apontaram principalmente o maior número de projetos aprovados (referindo-se principalmente aos recursos do crédito do PRONAF), ao maior número de famílias atendidas dentro dos municípios e a maior organização da sociedade civil (Tabela 12). Chama a atenção, no entanto, a grande porcentagem (12\%) dos conselheiros que relataram não haver qualquer tipo de mudança com a criação dos CMDRS. Não houve associação estatística entre os diferentes benefícios citados e o tipo de representação (sociedade civil ou poder público).

Tabela 12 - Principais benefícios desencadeados pelas ações do CMDRS nos municípios do território Portal da Amazônia de acordo com os conselheiros.

\begin{tabular}{l|c}
\hline \multicolumn{1}{c|}{ Benefícios citados } & $\begin{array}{c}\text { \% em relação ao total } \\
\text { respondente }\end{array}$ \\
\hline Maior número de projetos, iniciativas e benefícios & 45,10 \\
Maior organização & 20,59 \\
Coerência com as novas políticas & 4,90 \\
Maior informação & 2,94 \\
Não houve mudança & 12,75 \\
Não soube/ Não respondeu & 2,94 \\
\hline Total & 100,00 \\
\hline
\end{tabular}

Abramovay (2001) destaca que grande parte dos conselhos municipais de desenvolvimento rural formou-se a partir de 1997, como condição para o repasse dos recursos do Programa Nacional de Fortalecimento da Agricultura Familiar (PRONAF). O autor ressalta que estes conselhos teriam a função de transformar o PRONAF de um simples programa de crédito em um programa de desenvolvimento sustentável. Entretanto, o caráter prioritariamente consultivo e seu funcionamento como repassador de recursos não está permitindo atingir este objetivo.

É interessante analisar que esta não é uma característica exclusiva dos CMDRS. Pesquisas realizadas por Pipitone et al. (2003) e Gerschman (2004) indicam um quadro similar em Conselhos Municipais de Alimen- 
1032 - Participação e cultura política: os conselhos municipais de desenvolvimento rural sustentável no território Portal da Amazônia

tação Escolar e em Conselhos Municipais de Saúde. Estas pesquisas reforçam o quadro que os conselhos muitas vezes são entendidos como instituições para legitimar decisões tomadas em outras instâncias.

Com relação aos entraves principais citados pelos conselheiros, cerca de $68 \%$ citaram aspectos relacionados ao funcionamento dos conselhos, principalmente relacionado à falta de recursos para deslocamento e para a elaboração de projetos próprios. Deve-se reforçar que os representantes da sociedade civil moram principalmente nas áreas rurais, dificultando seu acesso às reuniões ou para a obtenção de informações. Este fato pode explicar ainda a participação somente no CMDRS dos representantes da sociedade civil, em contraposição aos representantes do poder público, que tendem a participar de mais de um conselho. Desta forma, um dos pontos levantados pelos entrevistados foi a necessidade de descentralizar as reuniões dos CMDRS, realizando-as em comunidades rurais e não apenas na sede do município.

Cerca de $40 \%$ dos conselheiros apontaram ainda problemas com referência à pouca participação da população nos conselhos. Os motivos citados foram um possível desinteresse, desinformação e a falta de união entre os moradores. Também não foi identificada associação estatística entre o tipo de representação e os diferentes entraves citados para o funcionamento dos CMDRS.

Schneider et al. (2004) apresentam algumas limitações importantes e que contribuem de forma decisiva para a situação identificada nos CMDRS do território Portal da Amazônia. Destacam a dependência dos conselhos em relação aos fundos de instâncias estaduais e federais, que acaba pré-formatando e pautando as discussões destes órgãos, e os limites da paridade participativa entre agricultores e membros dos poderes públicos, pois estes exercem suas funções de forma remunerada, dispondo de tempo e de uma formação reconhecida como adequada para o manejo dos instrumentos burocráticos no âmbito do estado. Abramovay (2003) reforça ainda a delimitação municipal dos conselhos de desenvolvimento rural uma vez que, embora o município seja em princípio uma esfera propícia para os cidadãos poderem controlar a vida pública, ele não constitui uma unidade pertinente para a mobilização de recursos e criação de laços sociais em vista da inovação e do desenvolvimento.

RER, Rio de Janeiro, vol. 45, no 04, p. 1013-1035, out/dez 2007 - Impressa em novembro 2007 


\section{Conclusões}

Os dados apresentados permitem concluir que os membros dos CMDRS dos municípios que formam o Portal da Amazônia constituemse em uma elite local, principalmente no tocante à cultura política. No entanto, observam-se diferenças importantes entre os representantes da sociedade civil e do poder público indicando uma distribuição desigual dos recursos políticos entre seus participantes além de problemas com referência à representatividade e ao exercício de participação dentro dos conselhos. Como propostas para aprimoramento deste órgão foram identificadas a necessidade de capacitação e a definição de novas estratégias para estimular a participação da população local, como a descentralização do local de realização das reuniões e a necessidade de apoio para locomoção dos representantes da sociedade civil.

\section{Referências Bibliográficas}

ABRAMOVAY, R. Conselhos além dos limites. In: SEMINÁRIO DE DESENVOLVIMENTO LOCAL E CONSELHOS MUNICIPAIS DE DESENVOLVIMENTO RURAL, 1, 2001, Anais..., Porto Alegre: Brasil, 2001, mimeo. ABRAMOVAY, R., O futuro das regiões rurais, Série Estudos Rurais, Porto Alegre: Editora da UFRGS, 2003.

BAVA, S. C. A reapropriação das cidades: a democratização e a descentralização das cidades são uma resposta à crise de governabilidade que o predomino da lógica de mercado impôs aos governos e à sociedade. Cadernos Le Monde Diplomatique, n. 2, p. 18-21, 2001.

COSTA, S. Esfera pública, redescoberta da sociedade civil e movimentos sociais no Brasil. Uma abordagem tentativa. Novos Estudos CEBRAP, n. 38, p. 38-52, 1994.

CASTRO, H. C. O. Cultura política, democracia e hegemonia: uma tentativa de explicação do comportamento político não-democrático. 2000. Disponível em: < http://www.acessa.com/gramsci/?page = visualiza r\&id $=\mathbf{1 0 2}>$. Acesso em: 25 de Jan. 2006 .

FUKS, M.; PERISSINOTTO, R. M.; RIBEIRO, E. A. Cultura política e de- 
1034 - Participação e cultura política: os conselhos municipais de desenvolvimento rural sustentável no território Portal da Amazônia

sigualdade: o caso dos conselhos municipais de Curitiba. Revista Sociologia e Política, n.21, p.125-145. 2003.

GERSCHMAN, S. Conselhos municipais de saúde: atuação e representação das comunidades populares. Cadernos de Saúde Pública, v.30, n.6, p. 1678-1681. 2004.

GOHN, M. G. O papel dos conselhos gestores na gestão urbana. In: RIBEIRO, A. C. T. et. al. Repensando a experiência urbana da América Latina: questões, conceitos e valores, 2000. p.175-201.

GOVERNO FEDERAL. Programa Nacional de Fortalecimento da Agricultura Familiar, Brasília: Ministério da Agricultura, do Abastecimento e da Reforma Agrária. 1995.

GREIF, A. Institutions and endogenous institutional change: historical institutional analysis. In: Seminário Brasileiro da Nova Economia Institucional, 2, 2001, Anais..., Campinas: Brasil, 2001.

IBGE - Instituto Brasileiro de Geografia e Estatística. Censo de 1996. Disponível em http://www.ibge.gov.br. Acesso em: 20 jan. 2006.

LABRA, M; FIGUEIREDO, I. Associativismo, participação e cultura cívica. O potencial dos Conselhos de Saúde. Ciência \& Saúde Coletiva, v. 7, n. 3, p. 537-547, 2002.

LAKATOS, E. M.; MARCONI, M. A. Fundamentos de metodologia científica. São Paulo: Atlas, 1996. 270p.

MARQUES, P. E. M.; FLEXOR, G. Conselhos municipais e políticas públicas de desenvolvimento rural: indagações em torno dos papéis sociais e ambientais da agricultura. 2006. Disponível em: http://www. nead.gov.br/tmp/encontro/cdrom/gt/3/Paulo_Eduardo_Moruzzi_Marques.pdf. Acesso em: 24 de jan. 2007.

MOISÉS, J. A. Os brasileiros e a democracia: bases sócio-políticas da legitimidade democrática. São Paulo: Ática, 1995.

PIPITONE, M. A.; OMETTO, A. M. H.;SILVA, M. V.; STURION, G. L.; FURTUOSO, M. C. O.; OETTERER, M. Atuação dos conselhos municipais de alimentação escolar na gestão do programa nacional de alimentação escolar. Revista Nutrição, v.16, n. 2, p.143-154, 2003.

RER, Rio de Janeiro, vol. 45, no 04, p. 1013-1035, out/dez 2007 - Impressa em novembro 2007 
SANTOS JÚNIOR, O. A.; Democracia e governo local: dilemas e reforma municipal no Brasil. Rio de Janeiro: Revan, 2001. 248p.

SCHNEIDER, S., SILVA, M. K. e MORUZZI MARQUES, P. E., Políticas públicas, participação social no Brasil rural, Série Estudos Rurais, Porto Alegre: Editora da UFRGS, 2004.

TATAGIBA, L. Conselhos gestores de políticas públicas e democracia participativa: aprofundando o debate. Rev. Sociol. Polít., v. 25, p. 209213, 2005.

WENDHAUSEN, A.; CAPONI, S. O diálogo e a participação em um conselho de saúde em Santa Catarina, Brasil. Cadernos Saúde Pública, v.18, n.6, p, 1621-1628, 2002.

Recebido em março de 2003 e revisto em dezembro de 2006. 